\title{
Adenosinergic Protection of Dopaminergic and GABAergic Neurons against Mitochondrial Inhibition through Receptors Located in the Substantia Nigra and Striatum, Respectively
}

\author{
Peter D. Alfinito, Sheng-Ping Wang, Lawrence Manzino, Sonia Rijhsinghani, Gail D. Zeevalk, and Patricia K. Sonsalla \\ Levine Neuroscience Laboratory, Department of Neurology, University of Medicine and Dentistry of New Jersey-Robert Wood Johnson Medical School, \\ Piscataway, New Jersey 08854
}

\begin{abstract}
Mitochondrial dysfunction may contribute to dopaminergic (DAergic) cell death in Parkinson's disease and GABAergic cell death in Huntington's disease. In the present work, we tested whether blocking $\mathrm{A}_{1}$ receptors could enhance the damage to DAergic and GABAergic neurons caused by mitochondrial inhibition, and whether blocking $\mathrm{A}_{2 \mathrm{a}}$ receptors could protect against damage in this model. Animals received an intraperitoneal injection of 8-cyclopentyl-1,3-dipropylxanthine ( $\mathrm{CPX})\left(\mathrm{A}_{1}\right.$ antagonist) or 3,7-dimethyl-1-propargylxanthine (DMPX) ( $\mathrm{A}_{2 \mathrm{a}}$ antagonist) $30 \mathrm{~min}$ before intrastriatal infusion of malonate (mitochondrial complex II inhibitor). Damage was assessed 1 week later by measuring striatal dopamine, tyrosine hydroxylase (TH), and GABA content. In mice and rats, malonate-induced depletion of striatal dopamine, TH, or GABA was potentiated by pretreatment with $1 \mathrm{mg} / \mathrm{kg} \mathrm{CPX}$ and attenuated by pretreatment with $5 \mathrm{mg} / \mathrm{kg}$ DMPX. To determine the location of the $\mathrm{A}_{1}$ and $\mathrm{A}_{2 \mathrm{a}}$ receptors mediating these effects, CPX or DMPX was infused directly into the striatum or substantia nigra of rats $30 \mathrm{~min}$ before intrastriatal infusion of malonate. When infused into the striatum, CPX (20 ng) potentiated, whereas DMPX (50 ng) prevented malonate-induced GABA loss, but up to $100 \mathrm{ng}$ of CPX or $500 \mathrm{ng}$ of DMPX did not alter malonateinduced striatal dopamine loss. Intranigral infusion of CPX (100 ng) or DMPX (500 ng), however, did exacerbate and protect, respectively, against malonate-induced striatal dopamine loss. Thus, $A_{1}$ receptor blockade enhances and $A_{2 a}$ receptor blockade protects against damage to DAergic and GABAergic neurons caused by mitochondrial inhibition. Interestingly, these effects are mediated by $A_{1}$ and $A_{2 a}$ receptors located in the substantia nigra for DAergic neurons and in the striatum for GABAergic neurons.
\end{abstract}

Key words: Parkinson's disease; Huntington's disease; neuroprotection; adenosine receptors; $\mathrm{A}_{2 \mathrm{a}}$ antagonist; $\mathrm{A}_{1}$ antagonist; malonate

\section{Introduction}

Parkinson's disease (PD) and Huntington's disease (HD) result from the loss of nigrostriatal dopaminergic (DAergic) and striatal GABAergic medium-sized spiny projection neurons, respectively. Although the precise cause of neuronal cell death in PD and HD is unclear, inhibition of mitochondrial function may play a major role (Parker et al., 1989; Gu et al., 1996). Understanding the mechanisms for protection of DAergic and GABAergic neurons against mitochondrial inhibition, therefore, should facilitate the development of treatments for PD and HD and may provide new insights into the causes of cell death in these disorders. In the present study, we explored adenosinergic protection of DAergic and GABAergic neurons against intrastriatal infusion of the mitochondrial complex II inhibitor malonate.

The effects of adenosine are conveyed by four G-protein-

\footnotetext{
Received Aug. 5, 2003; revised 0ct. 14, 2003; accepted 0ct. 15, 2003.

This work was supported by National Institutes of Health Grants AG08479, NS41545, and ES05022 and the American Parkinson's Disease Association.

Correspondence should be addressed to Dr. Peter D. Alfinito, Department of Neurology, University of Medicine and Dentistry of New Jersey-Robert Wood Johnson Medical School, 675 Hoes Lane, Piscataway, NJ 08854. E-mail: alfinipe@umdnj.edu.

Copyright $\odot 2003$ Society for Neuroscience $\quad$ 0270-6474/03/2310982-06\$15.00/0
}

coupled receptors classified as $A_{1}, A_{2 a}, A_{2 b}$, or $A_{3}$. Several studies have found that acute treatment with $A_{1}$ antagonists enhances ischemia-induced damage to either hippocampal or retinal neurons (de Mendonca et al., 2000). This work suggests that endogenous adenosine acting, at least in part, through $A_{1}$ receptors may function to protect neurons against toxic insults. Whether $A_{1}$ receptors exert a similar effect on nigrostriatal DAergic or striatal GABAergic neurons is unknown. Thus, one aim of the present work was to determine whether blocking $\mathrm{A}_{1}$ receptors could enhance the susceptibility of nigrostriatal DAergic or striatal GABAergic neurons to mitochondrial inhibition. To gain insight into how decreases in $A_{1}$ signaling may exacerbate DAergic or GABAergic cell damage during mitochondrial inhibition, we also sought to identify the location of the $A_{1}$ receptors mediating this effect.

Current evidence indicates that $A_{2 a}$ receptors may be viable targets for the treatment of $\mathrm{PD} . \mathrm{A}_{2 \mathrm{a}}$ receptor antagonists reverse motor disabilities in 1-methyl-4-phenyl-1,2,3,6-tetrahydropyridine (MPTP)-treated monkeys (Grondin et al., 1999) and protect against MPTP-induced DAergic cell damage in mice (Chen et al., 2001; Ikeda et al., 2002). It has been suggested, however, that the latter protective effect may be related to increased vesicular 
sequestration of 1-methyl-4-phenylpyridinium (the toxic metabolite of MPTP) (Ikeda et al., 2002). Therefore, we examined $A_{2 a}$ antagonist-mediated protection of nigrostriatal DAergic neurons using malonate, a mitochondrial inhibitor that does not get transported into DAergic vesicles (L. Manzino and P. K. Sonsalla, unpublished data).

$A_{2 a}$ receptor blockade protects GABAergic neurons against quinolinic acid-induced excitotoxicity (Popoli et al., 2002) and attenuates 3-nitropropionic acid (3-NP) (irreversible mitochondrial complex II inhibitor)-induced deficits in striatal lesion volume (Blum et al., 2003). There is, however, no direct neurochemical evidence showing that $A_{2 a}$ receptor blockade can protect GABAergic neurons against mitochondrial inhibition. Thus, we tested whether an $\mathrm{A}_{2 \mathrm{a}}$ antagonist could protect striatal GABAergic neurons against malonate treatment. To begin to understand how $\mathrm{A}_{2 \mathrm{a}}$ antagonists may protect DAergic or GABAergic neurons against mitochondrial inhibition, we also identified the location of the $\mathrm{A}_{2 \mathrm{a}}$ receptors mediating protection.

\section{Materials and Methods}

Drugs and treatment paradigms. Chemicals were purchased from Sigma (St. Louis, MO). Malonate was dissolved in water. The $\mathrm{A}_{1}$ antagonist 8-cyclopentyl-1,3-dipropylxanthine (CPX) and the $\mathrm{A}_{2 \mathrm{a}}$ antagonist 3,7dimethyl-1-propargylxanthine (DMPX) were dissolved in $45 \%(\mathrm{w} / \mathrm{v})$ 2-hydroxypropyl- $\beta$-cyclodextrin $(\beta$-CD) using sonication and moderate heating. Male Swiss-Webster mice (30-35 gm) and male Sprague Dawley rats $(300-375 \mathrm{gm})$ received intraperitoneal injection, intrastriatal infusion, or intranigral infusion of $\beta$-CD, CPX, or DMPX $30 \mathrm{~min}$ before intrastriatal infusion of normal saline or malonate. For mice, drugs were diluted with water to their final concentration in $9 \% \beta$-CD and injected intraperitoneally at 10 times their body weight. Rats received intraperitoneal injection of drugs in $45 \% \beta$-CD at two times their body weight. For direct intrastriatal or intranigral infusion, drugs were diluted with water to their final concentration in $10 \% \beta$-CD. Systemic and intracranial doses of CPX and DMPX used in the present study are known to have selectivity for $A_{1}$ and $A_{2 a}$ receptors, respectively, in the brain (Janusz and Berman, 1993; Phillis, 1995; Reggio et al., 1999; Chen et al., 2001).

Stereotaxic surgery and drug infusions. Surgeries and drug infusions in mice and rats were performed in accordance with previously developed models (Zeevalk et al., 1997; Moy et al., 2000). Cannulas were implanted just above the left striatum or substantia nigra $3-5 \mathrm{~d}$ before drug treatment. For mice, needle tip placement coordinates corresponded to those in the atlas of Slotnick and Leonard (1975) as follows: anteroposterior, 0.6 ; lateral, 2 ; dorsoventral, 3.5. Malonate $(6 \mu \mathrm{mol})$ was delivered by manually injecting $2 \mu \mathrm{l}$ of $3 \mathrm{~m}$ malonate over $1 \mathrm{~min}$.

For rats, needle tip placement coordinates corresponded to those in the atlas of Paxinos and Watson (1986) as follows: striatum, anteroposterior, -0.26; lateral, 3.4; dorsoventral, 5.3; nigra, anteroposterior, 5.3; lateral, 2.4; dorsoventral, 8.4. Malonate $(3 \mu \mathrm{mol})$ was delivered by infusing $1 \mu \mathrm{l}$ of $3 \mathrm{M}$ malonate over $2 \mathrm{~min}$ using an infusion pump (Stoelting, Chicago, IL). Concentrated solutions of CPX and DMPX were delivered similarly. The different amounts of malonate used in mice and rats reflect different sensitivities of these animals to malonate-induced damage (Albers et al., 1996; Zeevalk et al., 1997).

Striatal dopamine and GABA measurements. Striatal dopamine and GABA levels were measured 1 week after drug treatment using HPLC with electrochemical and fluorescent detection, respectively, as described previously (Sonsalla et al., 1987; Zeevalk et al., 1997). In rats, the striatum was subdivided into ventral, medial, and dorsal sections as detailed previously (Zeevalk et al., 2000), and each section was analyzed separately. In accordance with needle tip placement, only medial or dorsal sections of the striatum were damaged by malonate.

The right striatum from animals receiving intraperitoneal injections served as the $\beta$-CD control or to control for the effects of CPX or DMPX alone (see Figs. 1, 2). For animals receiving intrastriatal or intranigral infusion of CPX or DMPX, the right striatum from animals treated with malonate only served as the untreated control (see Figs. 3, 4). Treatment with $\beta$-CD (intraperitoneal, intrastriatal, or intranigral) had no effect on neurochemical measurements made 1 week after injection (data not shown).

Determination of striatal TH content. Tyrosine hydroxylase (TH), a marker for DAergic terminal degeneration, was measured using an ELISA similar to that described by Reinhard and O'Callaghan (1991). Ninety-six well microtiter plates (Thermo Labsystems, Franklin, MA) were incubated overnight at $4^{\circ} \mathrm{C}$ with monoclonal anti-TH (1:500; Calbiochem, San Diego, CA) in $8 \mathrm{~mm}$ sodium phosphate, $2 \mathrm{~mm}$ potassium phosphate, and $0.14 \mathrm{M}$ sodium chloride, $\mathrm{pH} 7.4$ (PBS). Wells were washed four times with PBS and then blocked for $1 \mathrm{hr}$ using $5 \%(\mathrm{w} / \mathrm{v})$ Carnation (Nestlé, Glendale, CA) nonfat dry milk in PBS. Striatal tissue samples were homogenized by sonication in PBS-0.5\% Triton X-100 (PBST) with $0.25 \%(\mathrm{w} / \mathrm{v})$ sodium lauryl sulfate. Purified TH protein (Cell 2 Cell, San Clemente, CA) was used to establish a standard curve. Samples and standards were incubated for $1 \mathrm{hr}$ at room temperature, washed four times with PBST, and then incubated for $1 \mathrm{hr}$ with both polyclonal anti-TH (1:500; Calbiochem) and polyclonal anti-rabbit horseradish peroxidase (HRP) (1:3000; Amersham Biosciences, Piscataway, NJ) in blocking solution. After washing four times with PBST, wells were incubated with Amplex Red (Molecular Probes, Eugene, OR) HRP substrate according to the protocol of the manufacturer. Reaction product was measured fluorometrically within the linear range of detection (excitation:emission ratio of 530:580 nm). Controls in which the monoclonal primary $\mathrm{TH}$ antibody, polyclonal secondary $\mathrm{TH}$ antibody, or tissue samples were omitted were not above background levels (data not shown).

Statistical analysis. Results were analyzed by one-way ANOVA with Newman-Keuls post hoc test using Prism software version 3.0 (GraphPad, San Diego, CA).

\section{Results}

\section{Adenosine $A_{1}$ receptor blockade potentiates the damage to DAergic and GABAergic neurons caused by intrastriatal infusion of malonate}

We have shown previously that intrastriatal infusion of malonate dose-dependently damages DAergic neurons in mice and both DAergic and GABAergic neurons in rats as evidenced by loss of striatal dopamine and GABA content (Albers et al., 1996; Zeevalk et al., 1997). In mice, intrastriatal malonate infusion decreased striatal dopamine levels by $45 \%$ compared with $\beta$-CD controls, but, as reported previously (Moy et al., 2000), it had no effect on striatal GABA content (Fig. $1 A$ ). Striatal TH levels in malonatetreated mice were also reduced by $41 \%$ compared with $\beta$-CD controls (Fig. 1 $\mathrm{A})$. Treatment with CPX $(0.25 \mathrm{mg} / \mathrm{kg}$, i.p. $) 30 \mathrm{~min}$ before intrastriatal infusion of malonate had no effect on striatal dopamine or GABA levels, but CPX (1 mg/kg, i.p.) potentiated the effect of malonate and reduced striatal dopamine levels by $69 \%$, TH content by $68 \%$, and GABA levels by $64 \%$ compared with $\beta$-CD controls (Fig. $1 A$ ). Treatment with CPX alone had no effect on striatal dopamine, TH, or GABA levels (Fig. 1A).

To confirm these results, we also tested the effect of CPX in rats. Intrastriatal infusion of malonate decreased striatal dopamine and GABA levels by 34 and 29\%, respectively, compared with $\beta$-CD controls (Fig. $1 B$ ). Animals given CPX ( $1 \mathrm{mg} / \mathrm{kg}$, i.p.) 30 min before malonate infusion showed a $63 \%$ decrease in striatal dopamine and a 52\% decrease in striatal GABA content compared with $\beta$-CD controls (Fig. $1 B$ ). CPX alone had no effect on striatal dopamine or GABA levels (Fig. $1 B$ ). 


\begin{abstract}
Adenosine $\mathrm{A}_{2 \mathrm{a}}$ receptor blockade protects DAergic and GABAergic neurons against the damage caused by intrastriatal infusion of malonate
\end{abstract} Using a competitive in vitro assay, we found that malonate does not affect tritiated dopamine uptake into isolated striatal synaptic vesicles $\left(\mathrm{IC}_{50}, 55 \mathrm{~mm}\right.$ ) (Manzino and Sonsalla, unpublished data). Thus, we used malonate to test whether $A_{2 a}$ receptor blockade could protect DAergic neurons directly against mitochondrial inhibition. Intrastriatal infusion of malonate in mice decreased striatal dopamine and TH content by 60 and $40 \%$, respectively, compared with $\beta$-CD controls (Fig. 2A). Malonateinduced toxicity was attenuated by acute pretreatment with DMPX (5 mg/kg, i.p.); compared with $\beta$-CD controls, dopamine levels fell by $45 \%$, and $\mathrm{TH}$ levels decreased only $10 \%$ (Fig. 2 A). In similar experiments with rats, intrastriatal infusion of malonate reduced striatal dopamine levels by $68 \%$, and pretreatment with DMPX attenuated this loss (Fig. 2B). DMPX alone had no effect on striatal dopamine or TH levels in mice (Fig. 2A) or on dopamine content in rats (Fig. $2 B$ ).

$A_{2 a}$ receptor blockade can reduce the deficits in striatal lesion volume caused by systemic administration of 3-NP (Blum et al., 2003). Although this work suggests that $A_{2 a}$ receptor blockade can protect GABAergic neurons against mitochondrial inhibition, this has not been measured directly. Because malonate by itself had no effect on striatal GABA levels in mice (Fig. $1 A$ ), these experiments were performed in rats. Intrastriatal infusion of malonate decreased striatal GABA levels by $27 \%$ compared with $\beta$-CD controls. Acute pretreatment with DMPX (5 mg/kg, i.p.) completely blocked malonate-induced GABA loss (Fig. $2 B$ ). DMPX alone had no effect on striatal GABA content(Fig. $2 B$ ).

\section{Adenosinergic effects on malonate-induced damage to GABAergic and DAergic neurons occur through receptors located in the striatum and substantia nigra, respectively} To begin to understand how $\mathrm{A}_{1}$ and $\mathrm{A}_{2 \mathrm{a}}$ receptor blockade modulates the damage caused by intrastriatal infusion of malonate, we sought to identify the location of the receptors mediating these effects. To test the role of striatal $A_{1}$ and $A_{2 a}$ receptors, $\beta$-CD (10\%, vehicle), CPX, or DMPX was infused directly into the striatum $30 \mathrm{~min}$ before intrastriatal infusion of malonate. Treatment with either 20 or $100 \mathrm{ng}$ of CPX did not alter the effect of malonate on striatal dopamine levels ( $20 \mathrm{ng}$; data not shown), but 20 ng of CPX potentiated malonate-induced GABA loss (Fig. $3 A$ ). Similarly, intrastriatal infusion of 50, 200, or $500 \mathrm{ng}$ of DMPX did not attenuate malonate-induced striatal dopamine loss (50 and $200 \mathrm{ng}$; results not shown), but $50 \mathrm{ng}$ of DMPX completely blocked malonate-induced GABA loss (Fig. $3 B$ ). Intrastriatal infusion of $20 \mathrm{ng}$ of CPX or $50 \mathrm{ng}$ of DMPX with intrastriatal infusion of saline had no effect on striatal GABA levels (data not shown).
To test whether $A_{1}$ and $A_{2 a}$ receptors in the substantia nigra could protect DAergic neurons against striatal energy impairment, animals were given an intranigral infusion of $10 \% \beta$-CD, CPX, or DMPX 30 min before intrastriatal malonate infusion. Treatment with 20 ng of CPX had no effect on malonate-induced striatal dopamine loss (data not shown), but 100 ng of CPX potentiated dopamine loss (Fig. $4 \mathrm{~A}$ ). Intranigral infusion of $50 \mathrm{ng}$ of DMPX did not protect against malonate-induced depletion of striatal dopamine (data not shown), but 500 ng of DMPX attenuated the effect of malonate (Fig. $4 B$ ). Intranigral infusion of 100 ng of CPX or $500 \mathrm{ng}$ of DMPX with intrastriatal infusion of saline had no effect on striatal dopamine levels (data not shown).

\section{Discussion}

We present the findings that pharmacological blockade of adenosine $\mathrm{A}_{1}$ receptors exacerbates the damage to nigrostriatal DAergic and striatal GABAergic neurons caused by intrastriatal infusion of malonate and that blockade of $\mathrm{A}_{2 \mathrm{a}}$ receptors protects against damage in this model. We have also shown that these effects are mediated through $\mathrm{A}_{1}$ and $\mathrm{A}_{2 \mathrm{a}}$ receptors located in the striatum for GABAergic neurons and, although actions of malonate occur in the striatum, it is $A_{1}$ and $A_{2 a}$ receptors in the substantia nigra that mediate these effects on DAergic neurons. These results support a therapeutic potential for $\mathrm{A}_{2 \mathrm{a}}$ antagonists in the treatment of PD or HD and lend insight into the mechanism by which $A_{1}$ and $A_{2 a}$ receptors modulate the damage to DAergic and GABAergic neurons caused by mitochondrial inhibition. Furthermore, our results suggest that decreases in $A_{1}$ signaling may enhance the susceptibility of DAergic and GABAergic 
A - IP DMPX (Mice)
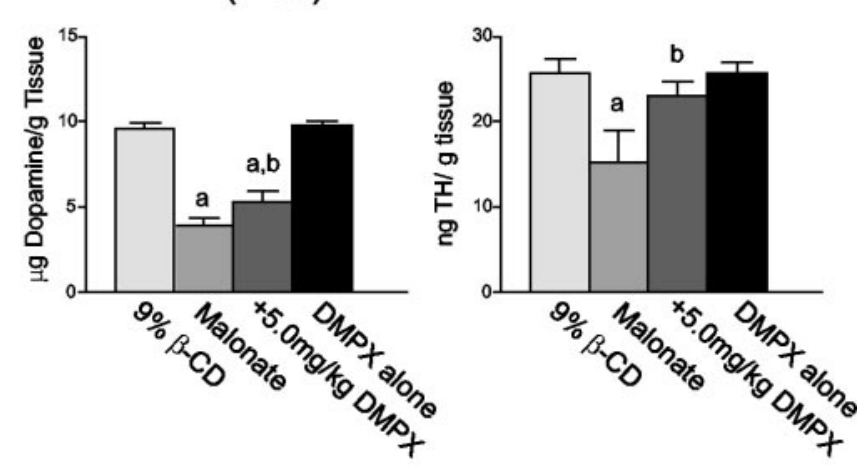

B - IP DMPX (Rats)
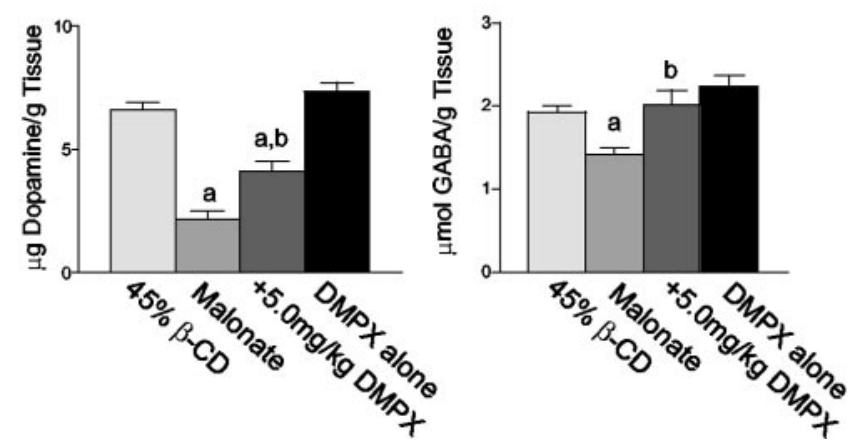

Figure 2. Blocking $A_{2 a}$ receptors protects against malonate-induced damage to DAergic and GABAergic neurons. $A$, In mice, pretreatment with intraperitoneal (IP) DMPX protected against malonate-induced $(6 \mu \mathrm{mol})$ depletion of striatal dopamine and TH levels $(n=12-13$ mice for dopamine; $n=6-9$ mice for TH). $B$, In rats, malonate-induced ( $3 \mu \mathrm{mol}$ ) depletion of striatal dopamine and GABA levels was attenuated by pretreatment with intraperitoneal DMPX. Dorsal striatum, $n=11-12$ rats for dopamine and $n=10$ rats for GABA. DMPX alone had no effect on striatal dopamine, TH, or GABA levels in mice or rats. Mean \pm SEM; ${ }^{a} p<0.05$ versus $\beta$-CD; ${ }^{b} p<0.05$ versus malonate.

neurons to toxic insults. This finding may provide new insight into the potential causes of neuronal cell death in PD or HD.

\section{Relevance of $A_{1}$ and $A_{2 a}$ receptor blockade to}

neurodegenerative disease

The role that $\mathrm{A}_{1}$ receptors may play in the etiology of $\mathrm{PD}$ or HD has received little attention. Results from the present study, however, raise the possibility that decreases in $A_{1}$ signaling could contribute to the development of PD or HD by making DAergic or GABAergic neurons more vulnerable to toxic insults, oxidative stressors, or injury. A decrease in $A_{1}$ signaling might result from genetic mutations, as has been suggested to occur in familial obesity (LaNoue and Martin, 1994), or could be related to aging. An age-related decline in $A_{1}$ signaling occurs in both the striatum and hippocampus (Jin et al., 1993; Corsi et al., 1997), where $\mathrm{A}_{1}$ mediated inhibition of neurotransmitter release was shown to be reduced in aged rats compared with young rats. Interestingly, aging appears to increase the susceptibility of nigrostriatal DAergic and striatal GABAergic neurons to the damage caused by malonate or quinolinic acid treatment (Beal et al., 1993; Figueredo-Cardenas et al., 1997). Whether these effects could be related to changes in $A_{1}$ signaling and whether $A_{1}$ signaling has a role in $\mathrm{PD}$ or $\mathrm{HD}$ remain to be tested.

Defects in mitochondrial function have been detected in PD and HD patients (Parker et al., 1989; Gu et al., 1996) and may contribute to cell death in these diseases. Our results show that
A - Intrastriatal CPX

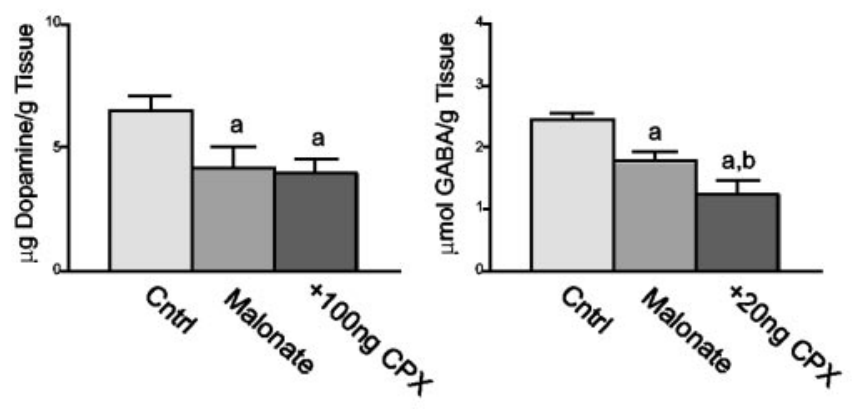

B - Intrastriatal DMPX

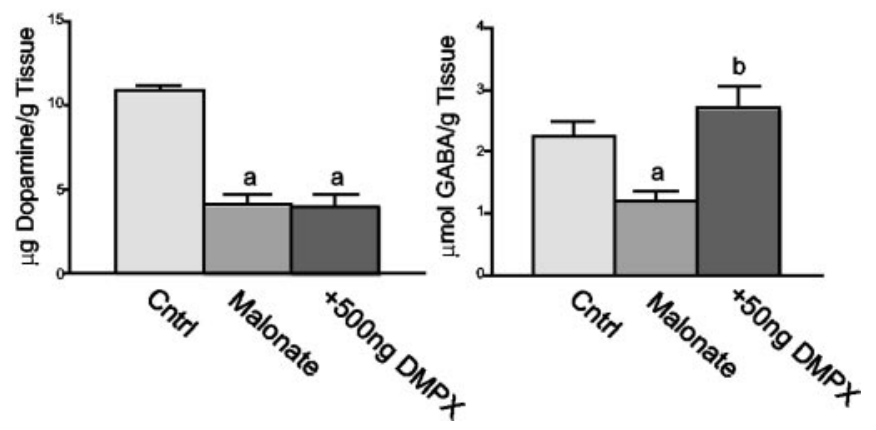

Figure 3. $A_{1}$-and $A_{2 a}$-mediated effects on GABAergic but not DAergic neurons occur through receptors located in the striatum. $A$, Intrastriatal infusion of CPX had no effect on malonateinduced depletion of striatal dopamine levels but potentiated the effect of malonate $(3 \mu \mathrm{mol})$ on striatal GABA content. Dorsal striatum, $n=5-6$ rats for dopamine; medial striatum, $n=$ 7-8 rats for GABA. B, Intrastriatal infusion of DMPX did not protect against malonate-induced dopamine loss but completely blocked GABA loss. Medial striatum, $n=6$ rats for dopamine and $n=5-6$ rats for GABA. Mean \pm SEM; ${ }^{a} p<0.05$ versus $\beta$-CD; ${ }^{b} p<0.05$ versus malonate. Cntrl, Untreated control.

\section{A - Intranigral CPX}

\section{B - Intranigral DMPX}
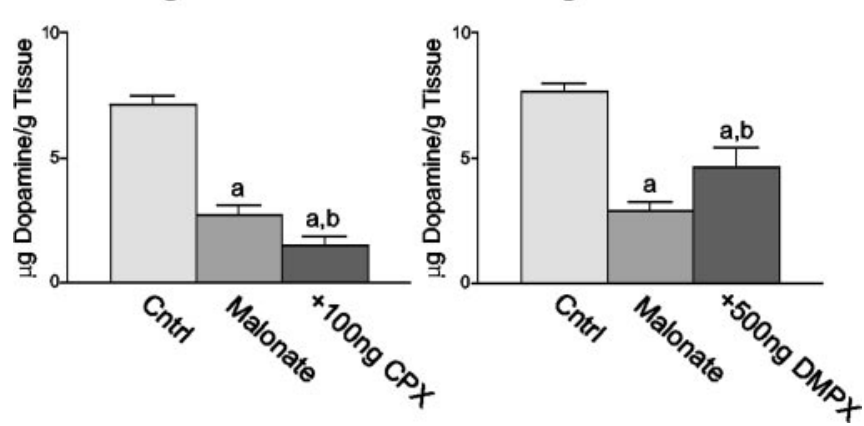

Figure 4. $A_{1}$ - and $A_{2 a}$-mediated effects on DAergic neurons occur through receptors located in the substantia nigra. $A$, Intranigral infusion of (PX potentiated malonate-induced ( $3 \mu \mathrm{mol}$ ) depletion of striatal dopamine. Dorsal striatum, $n=12-15$ rats. B, Intranigral infusion of DMPX attenuated malonate-induced depletion of striatal dopamine content. Dorsal striatum, $n=$ $9-11$ rats. Mean \pm SEM; ${ }^{a} p<0.05$ versus $\beta$-CD; ${ }^{b} p<0.05$ versus malonate. Cntrl, Untreated control.

acute, prophylactic treatment with an $\mathrm{A}_{2 \mathrm{a}}$ receptor antagonist can protect DAergic and GABAergic neurons against the damage caused by mitochondrial inhibition and support the idea that $A_{2 a}$ antagonists may be useful treatments for slowing cell loss in PD or HD. Effective treatments, however, must be capable of protecting DAergic or GABAergic neurons in the context of ongoing damage and progressive neuronal cell loss and must remain effective when administered chronically. Whether $\mathrm{A}_{2 \mathrm{a}}$ antagonists can protect DAergic or GABAergic neurons under these con- 
ditions remains to be tested in chronic animal models of PD and HD.

\section{Potential mechanism for $\mathrm{A}_{1}$ - and $\mathrm{A}_{2 \mathrm{a}}$-mediated effects on malonate-induced damage to DAergic and GABAergic neurons}

$A_{1}$ and $A_{2 a}$ receptors are expressed throughout the brain, including the striatum and substantia nigra (Fastbom et al., 1986; Johansson and Fredholm, 1995). Our results demonstrate that blocking $\mathrm{A}_{1}$ and $\mathrm{A}_{2 \mathrm{a}}$ receptors in the striatum exacerbates and protects against, respectively, malonate-induced damage to GABAergic neurons. These effects are likely to occur through $\mathrm{A}_{1}$-mediated stimulation and $\mathrm{A}_{2 \mathrm{a}}$-mediated inhibition of striatal glutamate signaling. Using in vivo microdialysis, Messam et al. (1995) demonstrated that intrastriatal infusion of malonate increases extracellular glutamate levels in the striatum. Malonateinduced damage to striatal neurons is also potentiated by coadministration of NMDA (glutamate NMDA receptor agonist) and attenuated by cotreatment with the NMDA receptor antagonist MK-801 [(+)-5-methyl-10,11-dihydro-5H-dibenzo [a,d] cyclohepten-5,10-imine maleate] (Maragos and Silverstein, 1995; Zeevalk et al., 2000). Whether blockade of $A_{1}$ or $A_{2 a}$ receptors in the striatum can potentiate or inhibit, respectively, malonate-evoked glutamate release in the striatum is unknown. Current evidence, however, supports such a mechanism. Previous work has shown that blocking presynaptic $A_{1}$ receptors in the striatum increases excitatory neurotransmission to GABAergic neurons (Flagmeyer et al., 1997), and that blocking $\mathrm{A}_{2 \mathrm{a}}$ receptors protects striatal neurons against quinolinic acid-induced damage by inhibiting presynaptic glutamate release (Popoli et al., 2002).

Interestingly, the effects of CPX and DMPX on malonateinduced damage to DAergic neurons were found to occur through receptors located not within the striatum but rather within the substantia nigra. Although these effects may reflect a direct action on DAergic neurons, $A_{1}$ and $A_{2 a}$ receptors have not been detected on these cells (Alexander and Reddington, 1989). An alternative possibility is that the $A_{1}$ and $A_{2 a}$ receptors are located on glutamatergic terminals in the substantia nigra and that modulation of malonate-induced damage occurs through $\mathrm{A}_{1}$-mediated stimulation and $\mathrm{A}_{2 \mathrm{a}}$-mediated inhibition of glutamate release. In fact, striatal energy impairment appears to damage DAergic neurons, at least in part, through stimulation of glutamate signaling in the substantia nigra. Elimination of glutamatergic afferents to the substantia nigra by subthalamic nucleus ablation has been found to protect DAergic neurons against intrastriatal infusion of 3-NP (Nakao et al., 1999). Our laboratory has also found that intrastriatal infusion of malonate increases extracellular glutamate levels in the substantia nigra, and that blocking nigral NMDA receptors protects DAergic neurons against intrastriatal infusion of malonate (P. D. Alfinito and P. K. Sonsalla, unpublished data). Whether $\mathrm{A}_{1}$ or $\mathrm{A}_{2 \mathrm{a}}$ receptor blockade can stimulate or inhibit, respectively, malonate-evoked glutamate release in the substantia nigra is currently under investigation in our laboratory. This effect seems possible, however, because $A_{1}$ receptors have been shown to regulate electrically evoked glutamate release in the substantia nigra (Shen and Johnson, 1997).

Nonspecific mechanisms of protection, such as blocking transporter-mediated uptake of malonate (Hassel et al., 2002), are not likely, because CPX, a methylxanthine with a structure similar to that of DMPX, was found to potentiate but not protect against malonate-induced damage, and because in some experiments, effects of CPX and DMPX were still observed when these drugs were infused into a different region of the brain than malonate.

\section{References}

Albers DS, Zeevalk GD, Sonsalla PK (1996) Damage to dopaminergic nerve terminals in mice by combined treatment of intrastriatal malonate with systemic methamphetamine or MPTP. Brain Res 718:217-220.

Alexander SP, Reddington M (1989) The cellular localization of adenosine receptors in rat neostriatum. Neuroscience 3:645-651.

Beal MF, Brouillet E, Jenkins B, Henshaw R, Rosen B, Hyman BT (1993) Age-dependent striatal excitotoxic lesions produced by the endogenous mitochondrial inhibitor malonate. J Neurochem 61:1147-1150.

Blum D, Galas MC, Pintor A, Brouillet E, Ledent C, Muller CE, Bantubungi K, Galluzzo M, Gall D, Cuvelier L, Rolland AS, Popoli P, Schiffmann SN (2003) A dual role of adenosine $\mathrm{A}_{2 \mathrm{a}}$ receptors in 3-nitropropionic acidinduced striatal lesions: implications for the neuroprotective potential of $\mathrm{A}_{2 \mathrm{a}}$ antagonists. J Neurosci 23:5361-5369.

Chen JF, Xu K, Petzer JP, Staal R, Xu YH, Beilstein M, Sonsalla PK, Castagnoli K, Castagnoli Jr N, Schwarzschild MA (2001) Neuroprotection by caffeine and $\mathrm{A}_{2 \mathrm{a}}$ adenosine receptor inactivation in a model of Parkinson's disease. J Neurosci 21:RC143(1-6).

Corsi C, Pazzagli M, Bianchi L, Della Corte D, Pepeu G, Pedata F (1997) In vivo amino acid release from the striatum of aging rats: adenosine modulation. Neurobiol Aging 18:243-250.

de Mendonca A, Sebastião AM, Ribeiro JA (2000) Adenosine: does it have a neuroprotective role after all? Brain Res Brain Res Rev 33:258-274.

Fastbom J, Pazos A, Probst, Palacios JM (1986) Adenosine $A_{1}$-receptors in human brain: characterization and autoradiographic visualization. Neurosci Lett 65:127-132.

Figueredo-Cardenas G, Chen Q, Reiner A (1997) Age-dependent differences in survival of striatal somatostatin-NPY-NADPH-diaphorasecontaining interneurons versus striatal projection neurons after intrastriatal injection of quinolinic acid in rats. Exp Neurol 146:444-457.

Flagmeyer I, Haas HL, Stevens DR (1997) Adenosine A receptor-mediated depression of corticostriatal and thalamostriatal synaptic potentials in vitro. Brain Res 778:178-185.

Grondin R, Bédard PJ, Tahar AH, Grégoire L, Mori A, Kase H (1999) Antiparkinsonian effect of a new selective adenosine $\mathrm{A}_{2 \mathrm{a}}$ receptor antagonist in MPTP-treated monkeys. Neurology 52:1673-1677.

Gu M, Gash MT, Mann VM, Javoy-Agid F, Cooper JM, Schapira AHV (1996) Mitochondrial defect in Huntington's disease caudate nucleus. Ann Neurol 39:385-389.

Hassel B, Bråthe A, Petersen D (2002) Cerebral dicarboxylate transport and metabolism studied with isotopically labeled fumarate, malate and malonate. J Neurochem 82:410-419.

Ikeda K, Kurokawa M, Aoyama S, Kuwana Y (2002) Neuroprotection by adenosine $\mathrm{A}_{2 \mathrm{a}}$ receptor blockade in experimental models of Parkinson's disease. J Neurochem 80:262-270.

Janusz CA, Berman RF (1993) Adenosinergic modulation of the EEG and locomotor effects of the $\mathrm{A}_{2}$ agonist, CGS 21680. Pharmacol Biochem Behav 45:913-919.

Jin ZL, Lee TF, Zhou SJ, Wang LCH (1993) Age-dependent change in the inhibitory effect of an adenosine agonist on hippocampal acetylcholine release in rats. Brain Res Bull 30:149-152.

Johansson B, Fredholm BB (1995) Further characterization of the binding of the adenosine receptor agonist $\left[{ }^{3} \mathrm{H}\right] \mathrm{CGS} 21680$ to rat brain using autoradiography. Neuropharmacology 34:393-403.

LaNoue KF, Martin LF (1994) Abnormal A 1 adenosine receptor function in genetic obesity. FASEB J 8:72-80.

Maragos WF, Silverstein FS (1995) The mitochondrial inhibitor malonate enhances NMDA toxicity in the neonatal rat striatum. Brain Res Dev Brain Res 88:117-121.

Messam CA, Greene JG, Greenamyre JT, Robinson MB (1995) Intrastriatal injections of succinate dehydrogenase inhibitor, malonate, cause a rise in extracellular amino acids that is blocked by MK-801. Brain Res 684:221-224.

Moy LY, Zeevalk GD, Sonsalla PK (2000) Role for dopamine in malonateinduced damage in vivo in striatum and in vitro in mesencephalic cultures. J Neurochem 74:1656-1665.

Nakao N, Nakai E, Nakai K, Itakura T (1999) Ablation of the subthalamic nucleus supports the survival of nigral dopaminergic neurons after nigro- 
striatal lesions induced by the mitochondrial toxin 3-nitropropionic acid. Ann Neurol 45:640-651.

Parker Jr WD, Boyson SJ, Parks JK (1989) Abnormalities of the electron transport chain in idiopathic Parkinson's disease. Ann Neurol 26:719-723.

Paxinos G, Watson C (1986) The rat brain in stereotaxic coordinates, Ed 2. New York: Academic.

Phillis JW (1995) The effects of selective $A_{1}$ and $A_{2 a}$ adenosine receptor antagonists on cerebral ischemic injury in the gerbil. Brain Res 705:79-84.

Popoli P, Pintor A, Domenici MR, Frank C, Tebano MT, Pèzzola A, Scarchilli L, Quarta D, Reggio R, Malchiodi-Albedi F, Falchi M, Massotti M (2002) Blockade of striatal adenosine $\mathrm{A}_{2 \mathrm{a}}$ receptor reduces, through a presynaptic mechanism, quinolinic acid-induced excitotoxicity: possible relevance to neuroprotective interventions in neurodegenerative diseases in the striatum. J Neurosci 22:1967-1975.

Reggio R, Pèzzola A, Popoli P (1999) The intrastriatal injection of an adenosine $\mathrm{A}_{2}$ receptor antagonist prevents frontal cortex EEG abnormalities in a rat model of Huntington's disease. Brain Res 831:315-318.
Reinhard Jr JF, O'Callaghan JP (1991) Measurement of tyrosine hydroxylase apoenzyme protein by enzyme-linked immunosorbent assay (ELISA): effects of 1-methyl-4-phenyl-1,2,3,6-tetrahydropyridine (MPTP) on striatal tyrosine hydroxylase activity and content. Anal Biochem 196:296-301.

Shen KZ, Johnson SW (1997) Presynaptic GABA $A_{B}$ and adenosine $A_{1}$ receptor regulate synaptic transmission to rat substantia nigra reticulate neurons. J Physiol (Lond) 505:153-163.

Slotnick BM, Leonard CM (1975) A stereotaxic atlas of the albino mouse forebrain. Washington, DC: United States Government Printing Office.

Sonsalla PK, Youngster SK, Kindt MV, Heikkila RE (1987) Characteristics of 1-methyl-4-(2'-methylphenyl)-1,2,3,6-tetrahydropyridine-induced neurotoxicity in the mouse. J Pharmacol Exp Ther 242:850-857.

Zeevalk GD, Manzino L, Hoppe J, Sonsalla P (1997) In vivo vulnerability of dopamine neurons to inhibition of energy metabolism. Eur J Pharmacol 320:111-119.

Zeevalk GD, Manzino L, Sonsalla PK (2000) NMDA receptors modulate dopamine loss due to energy impairment in the substantia nigra but not striatum. Exp Neurol 161:638-646. 